\title{
BUSINESS NEGOTIATIONS: COMMUNICATION IN THE BARGAINING PROCESS
}

\author{
Tatjana PÕLAJEVA \\ Tallinn School of Economics and Business Administration, \\ Tallinn University of Technology \\ E-mail: tatjana.polajeva@gmail.com
}

Reviewed book: Kęstutis Peleckis. Business negotiations: communication in the bargaining process: monograph. North Charleston, USA: CreateSpace, 2016. 224 p.

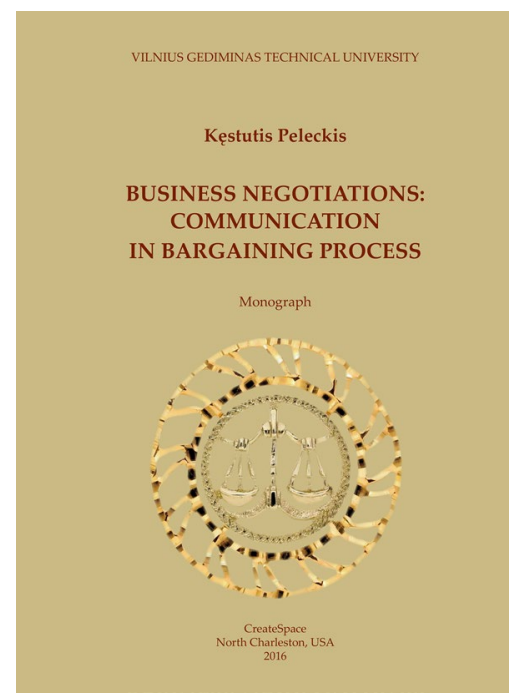

\section{Introduction}

The aim of this book is to present a holistic discussion and analysis in the field of business negotiations. Business negotiations are a diversified process, which combine different, and at the same time conflicting, interests of the negotiating parties. The success of business negotiations and meetings is highly dependent on communication competence, knowing the psychology of the other person or negotiating partner and, at the same time, keeping in mind the interests of the organization a person is representing. To manage 
this process properly, one needs to understand the basics of communication, as well as be able to value verbal and non-verbal communication signs and expressions. At the same time, one must be able to arrange a system to prepare interviews and negotiations, in addition to receiving and providing information to demonstrate one's positions. The author provides the most important theoretical issues of communication in the bargaining process, explains the main circumstances of communication efficiency and the components of effective communication. In addition, in the monograph, the reader can find a wide scope of rhetorical argumentation, strategic and convincing orientation of communication. This investigation also discusses the issues of building confidence in the bargaining process and how to identify and neutralize the opponent's remarks and possible manipulations. Also, the book provides the basics of reading and managing body language. The monograph provides numerous illustrations and examples. Finally, who will be interested in this monograph? It might be interesting for the professionals working in academic and practical areas: academic staff, working in the field of social sciences and humanities, investigating the issues of improving business negotiations and organizing business meetings, and for the management and administration specialists. In addition, it might be of interest for the representatives of various general segments of the society. The book may be used for university studies for improving students' negotiating competencies, as well as solving many practical questions of organizing and improving business negotiations.

\section{Content of the book}

This monograph consists of nine comprehensible chapters, where the author gives an overview of business negotiations and analyzes the most important viewpoints of communication in the bargaining process. Each chapter contains conclusions. It really helps the reader on one hand, to focus on the main results, outcomes of the chapter, and on the other hand to have a brief overview of the book. In addition, each chapter has its own list of the references.

In Chapter 1 "The principles of effective communication in the bargaining process" business communication and negotiating parties are described. The role of each party in the process is pointed out. The author shows different approaches how parties are trying to convince each other of the validity of their views and positions. This purpose involves using a variety of measures, from scientifically-approved principles and logic diagrams to various appeals, speculations and sophistries. Persuasiveness is a very important competence of the negotiator, therefore the author very detailed focuses on this aspect of negotiations, providing reader different standpoints. It is pointed out that nothing can replace the suggestibility of a spoken word. As a rule, only direct communication, negotiations, providing proof, arguments and counter-arguments allow the controverting parties to move quickly towards the overall objective of the agreement. The purpose of persuasion is to change the opponent's behavior. What are the characteristics for selfconfidence? How to increase self-confidence? The answers on these questions are also given in this chapter. This chapter ends with eight conclusions, where the author sum ups the main viewpoints of the chapter. 
Chapter 2 "The methods to substantiate the negotiators' positions in business negotiations" analyzes the approaches of establishing the negotiators' positions. Business negotiations include at least two sides, who try to find a common goal and understanding. Finally, each negotiator has to justify his/her position and convince their opponent. Communication channels and forms in this century have been developing and changing very rapidly. However, eye-to-eye conversations and immediate negotiations don't lose their value. The most important negotiating agreements and going face-to-face will remain as relevant in the future as they are nowadays. This reason involves using such methods of establishing the negotiator's position as providing proof, argumentation, manipulation, bluffing, persuasion and suggestion. It is illustrated very clearly by the author, providing the figure "The logical diagram of the mechanisms of persuasion". The author provides an interesting description to show how verbal and non-verbal methods influence the bargaining process. Just as the previous chapter, this finishes with eight conclusions. The main conclusion to this chapter is very logical, it is rather important during negotiations to encourage an active conversation, follow the reaction of the opponent, and adapt your behavior to his/her reaction.

Chapter 3 "Rhetorical argumentation in business negotiations" focuses on the influence of the rhetorical effect to the other negotiating party. From the authors' point of view, a persuasive speech is a very important competence, since nothing can change a negotiator's live speech. Despite well-developed modern means of communication, for example the Internet and electronic negotiation support systems, negotiators still prefer to travel to another part of the world to hold direct negotiations. Only direct negotiations, providing evidence, arguments, counter-arguments and controversy, can enable negotiators to quickly move forward to the overall objective of the agreement. During a live bargaining process the negotiator demonstrates himself/herself, his/her appearance, manners, knowledge of the etiquette and ethics, mind, emotions, voice characteristics, gestures, movements, facial expressions, reactions and other ways of communication. In addition, it is pointed out that the two important factors for effective negotiations are the use of rhetorical tools in the bargaining process and the success of staying in contact. The author emphasizes that the classical rhetoric focuses on how to convince the other party, and the modern rhetoric focuses on dialogue, interaction between the speakers and harmonizing relations. The concluding remarks to this chapter are the following: a rather important issue is rhetorical ethics with concern keeping to morality, ethics, etiquette, the law, as well as the technical standards of language. During negotiations, certain rules and standards can be extended, supplemented or narrowed.

Chapter 4 "Strategic orientation of the negotiator's rhetoric in business negotiations" states that creating a strategic plan of the negotiating speech should focus on avoiding coincidences and selecting the most appropriate means to achieve its objective. The implementation of the strategic focus is related to each aspect of the speech. Negotiating, in other words, is public speaking in negotiations - a strategic process, which includes understanding the circumstances, deliberate behavior and planning on how to achieve goals.

During the time of negotiations, the negotiators create something together and have their thoughts, opinions, attitudes and values tested, adapted and developed through 
interaction. Different negotiators may have significantly different cultural approaches. It is very important to be aware of his/her cultural background. This is because some negotiators may perceive some facts and things as more important or more significant than others and this attitude will determine how they will interpret and understand the statements that they hear. The general conclusion of the chapter contains the following: the development of a strategic plan of a speech should distinguish its narrower aspect, the rhetorical situation. A rhetorical situation is characterized by the audience, the event, the speaker and finally the speech itself. A negotiating situation is defined by more factors: the negotiator/s (from both sides) the represented organization (from both sides), product or service, the need for negotiations, and finally, the rhetorical skills of the negotiators. The negotiating speech is presented as a response to a specific situation.

Chapter 5 "Self-presentation strategies in business negotiations" analyzes the phenomenon of self-presentation in business negotiations. It can be defined, as "a behavioral mode, which is used in public business surroundings to achieve an agreement and avoid repudiation by focusing on universally adapted norms and other people's expectations". In this chapter, the main self-presentation strategies (consolidating, defensive, ingratiating and self-humiliating) are described; they are used in business meetings and negotiations. The author has pointed out the advantages and disadvantages of the named strategies. It is interesting to point out that the motivation of self-presentation develops under public situations, since people are likely to take interests in people in order to find out their opinions on others. Therefore, a person, acting as a social entity, tries to observe himself/herself from the point of view of the others. He/she tries to make himself/herself acceptable and valuable. The author describes the understanding of self-presentation in detail, which influences both a person's identity and his/her state in business interaction. In addition, there are three groups of factors determining the choice of self-presentation: individual personal factors, inter-individual factors and situational (depending on social environment) factors, which may be conditionally attributed to external factors. All these factors are closely interconnected during the presentation, not only interacting, but also helping to make the decision on what are the most suitable forms of behavior for developing such an image. They help to select self-presentation strategies. For further research, the author points out some outside situational factors and the existing cultural and social norms, expectations and values, which could influence the presentation planning and performance.

Chapter 6 "Building trust in business negotiations". What can interfere with trust, as well as related stereotypes and substitutes? The answers on this question can be found in this chapter. The author describes the problems of building trust in business negotiations, pointing out that business negotiations involve risks, and trust helps to balance the situation. At the beginning of business negotiations, the negotiators are trying to understand their opponents according to their external image. The impression formed by the appearance of the negotiating partner is of great significance. Knowing one's opponent helps the negotiator to improve, because he/she improves his/her cognitive powers. In addition, cognitive accuracy and disclosure of the internal essence of the negotiating partner determines the course of the business meeting and the future results 
of the business negotiations. Opinions formed in advance can have a strong influence on understanding the opponent or interlocutor. They determine how information will be accepted and interpreted. Confidence has a positive effect on the relations in a group of negotiating organization representatives and relations between the negotiating parties. It liberates and mobilizes the actions of the negotiator, encourages creative and innovative activity with other people, reduces uncertainty and risk, as well as increases possible opportunities for action. Trust is necessary in order to feel whether the negotiating partner or interlocutor is inclined to betray. Trust is also necessary to harmonize and plan cooperation, as well as to ensure intentional venture and safe communication.

Chapter 7 "The opponent's remarks in business negotiations: identification and neutralization" discusses the questions of identifying and neutralizing opponents' remarks and contradictions in business negotiations. During the process of business negotiations, both parties try to convince each other, from the point of view of the validity and veracity of their views and positions. Due to this, there are various measures, from logical evidence, arguments, replies, comments, contradictions or various schemes to appeals, speculations, sophistries and manipulations to consider the different views and positions. For example, reasoning in business negotiations means playing certain role. By using particular statements and evidence, it is possible to convince the participant or the opponent to change their position or beliefs, taking the position of the other negotiating party. Various comments, objections and remarks are a natural part of business negotiations, which indicate that the opponent is listening and responding to the opinion and proposals made by the other negotiating party. There are different types of remarks and contradictions. The author shows an analysis of their reasons and origins, as well as methods and techniques to neutralize them. This chapter has many examples on different types of remarks. Sometimes, business negotiations rarely go by without any opponents' comments, contradictions and doubts. This reality cannot be avoided - on the contrary: these contradictions do not stop the discussion and may be useful, as they help to find out at least some of the doubts of the other negotiating party, ultimately helping to convince them. To conclude the chapter, the author points out that it is important to differentiate arguments and try to seek their favor.

Chapter 8 "Manipulation in business negotiations: identification and neutralization". This chapter focuses on discussions about the issues of how to recognize, identify and neutralize manipulation. Describes the concept of manipulation, analyses its motives and offers ways how to identify it. There are three manipulation methods. They can be divided into several groups, according to their target. The author provides several examples to each type of target. Within the process of negotiations, the parties are trying to convince each other that their viewpoints and statements are the correct ones. There are various measures, for example, logical proof, arguments and various schemes to appeals, speculation, sophistry and manipulations to achieve this. The author points out, that reasoning in negotiations means using certain statements and evidence in an attempt to convince the opponent to change their positions or beliefs and adopt the position of the other negotiating party. Being able to distinguish between serious evidence and attempts to manipulate in a bargaining process is crucial. The concluding remark of the 
chapter, given by the author, is that it is hard to recognize professional manipulation. It most likely means that this aspect of business negotiations is rather complicated.

Chapter 9 "Nonverbal communication in business negotiations" analyzes the importance of being able to read body language signals in business negotiations. Watching physical body changes and gestures can lead to a more or less realistic impression about the opponent, his/her feelings, mood, thoughts, expectations, intentions and their changes. The most important features of non-verbal body language are: posture, clothing, accessories, gestures, eye contact, facial expressions, smile, tone of voice, laughter, eye contact, eye signs, the distance between the participants of the conversation, touch, clap, dance, and physiological response: sweating palms or forehead, paleness, acute facial or neck redness, etc. Some of the non-verbal communication signs (body language) are conscious (either natural or pretended), while others are communicated to the environment unintentionally, with an immediate, instant and instinctive response to received information without any thinking. Each negotiator needs to develop his/her ability of body language via a theoretical approach through practical application.

\section{In conclusion}

I totally agree with the author, that business negotiation is an art, which includes different skills: communication, rhetoric, psychology, ethics, management, economics, etc. Combining this knowledge opens better communication possibilities and language options to reveal much more than is actually said and observed in the environment. Not everybody has the talent of public speech - the kind that ignites peoples' hearts and awakens their thoughts. Additionally, the words which we say to our negotiating partners do not always mean the same for them, as they do for us. Because we are different. The more communication tools we know, the more we increase our ability to understand the other people. We are aware of the theory, we are able to use body language, but how do we achieve our personal and organizational goals? That is why business negotiation is an art.

Hopefully the author will consider to research the cultural influence/impact on the communication in bargaining process.

I believe that the book "Business negotiations: communication in the bargaining process", written by Professor Kęstutis Peleckis (Vilnius Gediminas Technical University, Lithuania), can be interesting for professionals and for a wider audience. The reader will find something new. I recommend to have this monograph as a reference source.

I am happy to have had the opportunity to review this book.

Tatjana PÕLAJEVA, Prof. Dr Sc. Her research interests focus on economics, marketing, business communication, the role of public and business sectors in economic environment, and sustainable development. She published her papers in such journals as Journal of Management Development, Oeconomia Copernicana, International Journal of Learning and Change, Entrepreneurship and Sustainability Issues, Economics and Management, Baltiiski Region, and Belarus v Sovremennom Mire. 